\section{EUROPEAN COLLABORATION}

\section{Projects Galore}

Technologrcal cooperation among Europeans is taking a hammering-the air bus affair is just the latest of a number of disappointments among which ELDO is the classical example. But a series of proposals which is being put forward in spheres at once less controversial and less expensive than aviation and rocketry deserves a better fate. The proposals are embodied in the unpublished report of a working party to discuss the possibilities for scientific and technological cooperation within the EEC and between the EEC and other European countries. The working party has a chequered history (Nature, 221, 898; 1969). It began in October 1967 and was called the Maréchal group after its chairman, who was later replaced by Professor Pierre Aigrain of the Délégation Générale de la Recherche Scientifique in Paris. Last year the group downed tools after the French veto of British entry into the Six, because the Dutch and Italians felt the French attitude was not in the spirit of the aims of the working party. Last September they were persuaded to start again, and their report has now been approved by the Medium Term Economic Policy Committee of the EEC. It goes now to the European Council of Ministers.

Countries outside the EEC which have applied for entry were represented together with other interested countries such as Sweden and Switzerland. They were asked to investigate the scope for cooperation in data processing, telecommunications, new means of transport, oceanography, metallurgy, pollution (which includes noise pollution of the environment) and meteorology. Altogether forty-seven specific proposals are listed, costing $\$ 210$ million, and thirty-four of these are said to be sufficiently well understood for the European Council to be able to decide about them fairly soon. The list includes projects to develop a high speed computer, a European data processing institute and the use of software in various fields. A scheme for a network for data transmission between research centres, a European program library and committees for software standardization are said to be specific cnough for the council to come to an immediate decision. In most cases, cooperation with countries outside the EEC is thought to be desirable and for one project at least-a design study for a 2,000 ton hovercraft - the importance of collaboration with Britain is mentioned. There are some projects, however, notably in metallurgy, where the report says collaboration with countries outside the EEC is not particularly desirable, presumably to protect specific industries within the community-the development of materials for desalination and steel pressure vessels for the chemical industry, for example.

What the European Council of Ministers now has to do is decide which of the projects to back. Then the question will be how to finance them and, the most awkward problem in European cooperative ventures, which countries are to get the contracts. Many of the projects in the report may be held up by the lack of the standardization of European company law. The meteorological sphere would seem to be a good area to start with, because of the international links which are already well established. But one of the three proposals in meteorology-a European weather satellite-is likely to be too bedevilled with European space politics for much progress to be made. The other proposals, a meteorological research centre and cooperation in the development, standardization and purchase of instruments, have a better chance of success.

\section{PHYSICS \\ Europe Meets}

Nearly a thousand physicists from most countries of a slightly enlarged Europe converged on. Florence after Easter to attend the inaugural meeting of the European Physical Society. The theme of the five day symposium was the growth points in physics. Those who went in the hope of learning a wealth of new physics may have been slightly disappointed, but, for those who saw this meeting as a chance to rub shoulders with some of the more illustrious European physicists and to gain some insight into the wider trends of the subject, the trip to Florence was well worth while. The general nature of the title was a deliberate gesture, according to the secretary of the European Physical Society, Professor Laurens Jansen, to give physicists the widest pretext for attending the inaugural meeting.

After two stimulating introductory papers, on the old days at the Cavendish Laboratory by Professor P. M. S. Blackett, and on physics in the twentieth century by Professor V. F. Weisskopf, the meeting got its teeth into discussing the future of five of the principal branches of physics. It soon became clear that the spectacular advances in astrophysics in recent years reflected the most obvious growth point of physies, and Dr A. Hewish and Dr D. W. Sciama from Cambridge University delivered a comprehensive account of the latest developments in this subject.

In such a conference, nobody, of course, will admit to not working in a growing branch of the subject, but the general impression was that the nuclear physicists, who are ever eager to reach into the taxpayer's pocket for a new accelerator, gave a good account of themselves. If the mood of Florence is typical, and there was a large representation of nuclear physicists at the meeting, high energy physies in Europe still has quite a rosy future.

Much of the benefit of this type of conference, particularly to the younger participants, lies in the informal contacts that are made outside the framework of the lectures. The committee of the EPS recognizes that the society has a unique part to play as a forum for younger physicists to find out what is happening in physics in the wider European context. It is too early to say what the long term role of the EPS will be. There are two or three areas, however, where it is generally agreed that the society can make its influence felt, including, of course, the organization of conferences on a European scale. Europe may still be far from unified, but many physicists would see the natural unity of physics as allowing the world of science to gain a head start on the politicians.

The committee of the EPS also considers that it can act as a useful catalyst in forging a sensible policy for physies journals within Europe. Details of this and other administrative facets of the EPS received much attention at Florence, but the question of an officisl language is not settled. There is no shortage of ides: among the committee, but implementation is proving 
a problem, and the long term success will almost certainly depend on how much financial backing it can obtain. As one English professor put it, "I would gladly send one of my graduate students to an EPS meeting in Paris, but the cost of transport and the EPS conference fee comes to $£ 50$, which is prohibitive".

\section{NATURAL GAS}

\section{Dry Wells Yield Gas}

The Gas Council and Home Oil of Canada have announced plans for developing two natural gas wells in Yorkshire-they will be the first land based wells in Britain to feed the national grid directly with natural gas. If all goes according to plan, the Gas Council anticipates that gas should be flowing by the end of 1970 and that the initial rate of flow will be about 100 million cubic feet a day, or seven per cent of the total consumption of gas in the United Kingdom.

The Yorkshire gas exists in limestone strata known as Zechstein Dolomite. There are three geological layers which are host to the natural gas in the North Sea and the Yorkshire fields-both fields being part of the same basin. The North Sea gas comes from the upper and lower layers, known respectively as Bunter and Rotliegenders strata, and the middle layer supplies the Yorkshire wells. The theory of the Gas Council is that the gas is formed in a carboniferous layer and then rises into one of the three porous reservoir rocks. It is trapped there by an impermeable dome, which in the North Sea is often a form of rock salt.

Although earlier finds of land based natural gas in Britain date back as far as 1936, the quantities involved were small and were only used for the manufacture of town gas. The two Yorkshire wells, drilled in 1966 and 1968, represent deposits one or two orders of magnitude greater than any of the previous discoveries.

Home Oil is at present seeking planning permission from the North Riding of Yorkshire County Council to set up the necessary equipment at the well heads and to build the processing plant. The plan is that the gas should flow through an underground pipeline to a site near Ebberston Common where water would be extracted from the gas. It would then flow to the processing plant which would make the gas suitable for public supply. The wells apparently lie within the limits of the North Yorkshire Moors National Park, but the processing plant will be outside this area.

The cost of developing the two wells is estimated at $£ 3$ million. This includes the production of the two mile pipeline from the well heads to the processing plant. The gas flow will probably be linked to the national grid through the Newcastle-Leeds pipeline, which is nearly complete.

The partnership of Home Oil and the Gas Council has rather intricate origins. The Canadian company has an agreement with British Petroleum to drill in the part of the country which includes the new wells. The Gas Council also has an agreement with British Petroleum whereby any oil which is discovered belongs to BP and any deposits of gas to the Gas Council. Thus the Gas Council and Home Oil come out of the Yorkshire gas discovery as partners.

No firm estimate of the lifetime of the wells is yet available. The Gas Council is confident, however, that the deposits will last at least five years at the initial rate of flow.

\section{ROAD TRAFFIC \\ Cost of Dawdling}

THE motoring clubs have long alleged that traffic jams are as expensive as they are frustrating, and the Road Research Laboratory has now provided them with chapter and verse (The Effect of Road and Traffic Conditions on Fuel Consumption, RRL Report LR 226). The laboratory has measured the fuel consumption of six vehicles-ranging from a Vauxhall Viva to a 20 ton lorry-in a wide variety of road and traffic situations. Miles per gallon turned out to be maximum for cars at speeds around 35 miles per hour. At 10 miles per hour, consumption was twice the minimum. Curiously, consumption versus speed data derived from several types of urban and rural roads fell onto the same curve (see Fig. 1). But on motorways, fuel consumption was 10 to 20 per cent less than on other roads at the same average speed.

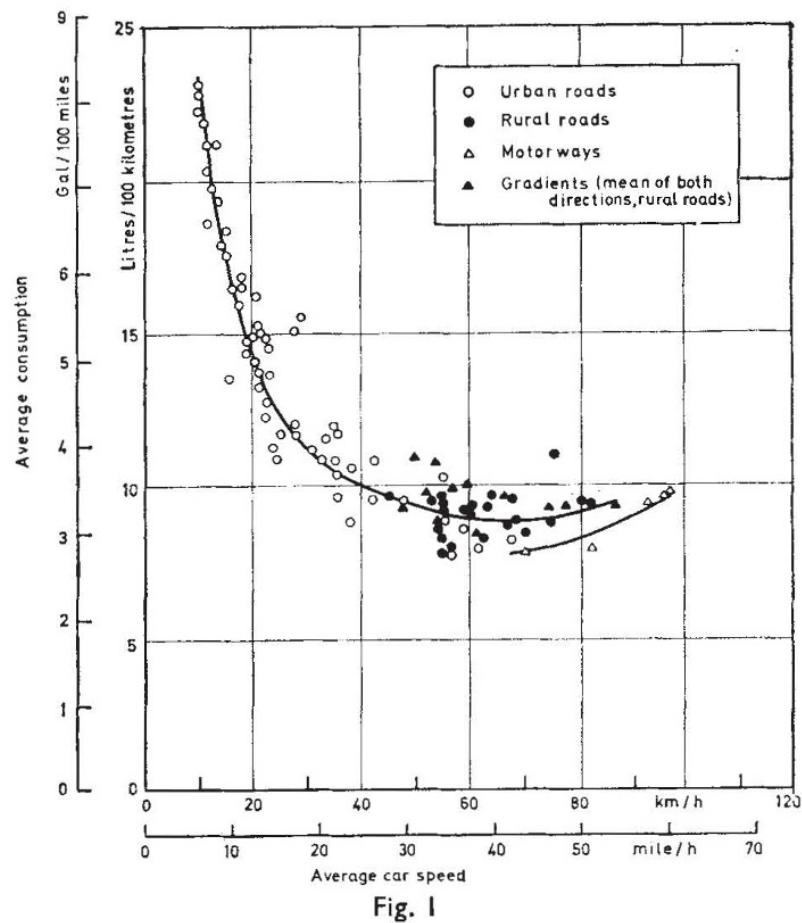

Heavy commercial vehicles gave a similar curve though, as would be expected, gradients had a bigger influence on performance. On a gradient of $6 \cdot 25$ per cent, the fuel consumption of a laden 20 ton lorry (averaged over trips up and down) increased by 125 per cent. A small car used 20 per cent more fuel on a 6.25 per cent gradient, and a large car (a Ford Zephyr) 30 per cent more.

The report bears out another item of motoring propaganda-the effect of driver's attitude on fuel consumption. In some test runs, drivers were given instructions ranging from "drive as economically as possible" to "drive as if you were in a hurry". The hurried drivers used, at a given speed, 10 to 20 per cent more fuel than the economical ones, largely because of a greater use of low gears. 